\title{
Great South African Molecules: The Case For Mycothiol
}

\author{
Comfort M. Nkambule \\ Department of Chemistry, Tshwane University of Technology, Pretoria, 0001, South Africa.
}

Received 13 September 2016, revised 15 March 2017, accepted 17 March 2017.

\begin{abstract}
South Africa has one of the oldest chemical societies in the world and has a long history of natural products, synthetic, and medicinal chemistry yet the visibility of molecules discovered or synthesized in South Africa is very low. Is this because South African scientists are incapable of discovering influential and celebrated molecules, or is there inadequate publicity of such discoveries? Perspective profiles on the discovery and scope of research on 'Great South African Molecules' should be a good start to redress this state of affairs. One such molecule deserving publicity is the antioxidant mycothiol which is produced by mycobacteria. This is a molecule of interest not only because of its medicinal potential in the fight against tuberculosis, but also from synthetic methodology and enzyme inhibition studies. This review aims to illuminate the scope of research in mycothiol chemistry for the purpose of promoting multidisciplinary investigations related to this South African molecule.
\end{abstract}

KEYWORDS

Mycothiol, Mycobacterium tuberculosis, great molecules, chemistry Nobel Prize.

\begin{tabular}{|c|c|}
\hline & of Contents \\
\hline 1 . & $\ldots \ldots \ldots+\cdots \cdots+$ \\
\hline 2. & Is Mycothiol a Great Molecule? \\
\hline 2.1. & Is Mycothiol a South African Molecule? . . . . . . \\
\hline 3. & Why is Mycothiol a Molecule of Great Potential? ..... \\
\hline 3.1. & Mycothiol's Significance to the ТВ Problem $\cdots \cdots \cdots \cdots \cdots \cdots \cdots \cdots \cdots \cdots \cdots \cdots \cdots \cdots$ \\
\hline 3.2. & Mycothiol Synthesis as a Synthetic Methodology Challenge $\ldots \ldots \ldots \ldots \ldots \ldots 74$ \\
\hline 3.3. & 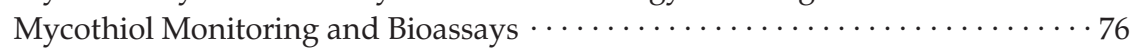 \\
\hline 4. & Conclusion $\ldots \ldots \ldots \ldots \ldots \ldots \ldots \ldots \ldots$ \\
\hline & References \\
\hline
\end{tabular}

\section{What is a Great Molecule?}

The diversity of organic chemical entities that have influenced and shaped human civilization is marvellous and includes synthetic molecules designed purely from the imagination of chemists or through serendipitous discoveries, but the majority have come from other organisms, terrestrial and marine alike, including plants, fungi, parasites, sponges and bacteria. ${ }^{1}$ In many cases these natural compounds have been modified into derivatives which have vastly different properties to the original, either by humans or by exposure to the elements. The impact of molecules covers all spheres of life including the key sectors of medicine (active pharmaceutical agents), nutrition (vitamins and supplements), clothing (polymers and fabrics), energy (lightand energy-harnessing molecules and fuels) and security (fabrics for personal protection against trauma, chemical and fire damage). The most influential molecules are linked directly to Nobel Prize awards in recognition of their significance (Fig. 1). These prizes have been awarded in the different categories of Chemistry [Chlorophyll (1915), haemin and chlorophyll (1930), vitamin A, vitamin B2 and vitamin C (1937), fullerenes (1996)], Physiology or Medicine [Prontosil (1939), vitamin K (1943), penicillin (1945), dichlorodiphenyltrichloroethane or DDT (1948), streptomycin (1952), prostaglandins (1982), artemisinin (2015) and the avermectins (2015)] and Physics [graphene (2010)]. ${ }^{2}$

Other molecules to which we might accord a status of 'great-

To whom correspondence should be addressed. E-mail: nkambulecm @ tut.ac.za ness' have garnered rock star-like popularity as blockbuster selling products or because of their massive impact in alleviating the dread of certain diseases and infections. Such is their celebrity that even the lay-person knows of these molecules, even if it is only by their trivial or trademark names. These include nylon (apparel, sheets and components), Kevlar (body armour and personal protection fabrics like motorcycle padded jackets), quinine (malaria), paclitaxel, known commonly as taxol (cancer), azidothymidine, commonly known by its abbreviation AZT (HIV-AIDS)m sildenafil commonly known by its trademark name Viagra (erectile dysfunction) and atorvastatin commonly known by its trademark name Lipitor (hypertension) (Fig. 2).

A common theme behind the success of these great molecules is the determination and perseverance of the scientists behind their discovery or application to be active advocates of their utility, significance and value to science or commerce. Recently Berhanu Abegaz wrote an insightful and stirring commentary on the challenges of doing chemistry in Africa, but on a positive note he also emphasized the opportunities for endeavours in chemistry on the African continent. ${ }^{3}$ This is indeed the story of the future of chemistry in Africa and the South African government must be acknowledged for the positive role they are playing in advancing support for these opportunities. The government has engaged various strategies and concepts to diversify the South African economy away from being intensive on resource supply to focus on the so-called beneficiation and knowledge 


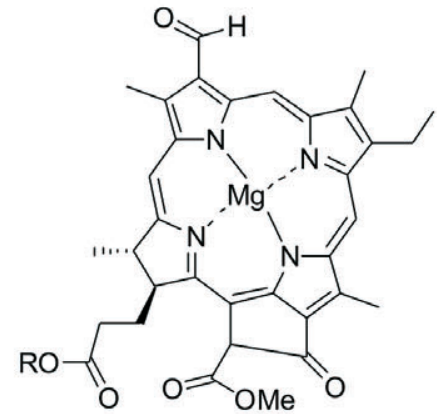

Chlorophyll 1915, 1930<smiles>CC1=C(/C=C/C(C)=C/C=C/C(C)=C/CO)C(C)(C)CCC1</smiles>

Vitamin A (e.g. Retinol) 1937<smiles>Nc1ccc(N=Nc2ccc(S(N)(=O)=O)cc2)c(N)c1</smiles>

Prontosil 1939

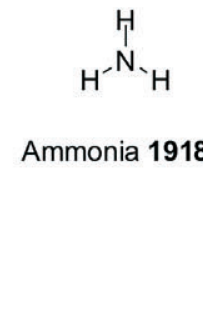<smiles>Cc1cc2nc3c(=O)[nH]c(=O)nc-3n(C[C@H](O)[C@H](O)[C@H](O)CO)c2cc1C</smiles>

Vitamin B2 1937

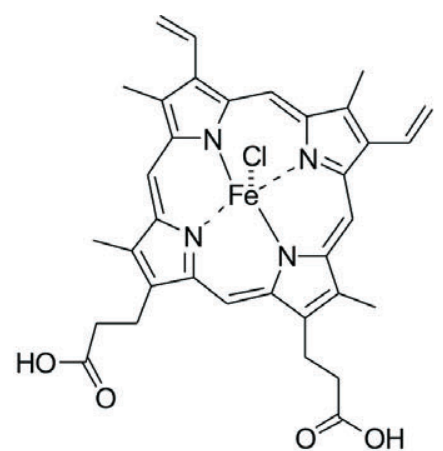

Haemin 1930<smiles></smiles>

Vitamin C 1937

Vitamin K (e.g. Vitamin $\left.\mathrm{K}_{1}\right) \mathbf{1 9 4 3}$<smiles>CC1=C(C/C=C(\C)C(C)(C)CCCC(C)C)C(=O)c2ccccc2C1=O</smiles><smiles>[R]C(=O)N[C@@H]1C(=O)N2[C@@H]1SC(C)(C)[C@H]2C(=O)O</smiles>

Penicillin 1945<smiles>C=C/C=C\C(=C/C)C(C(=C)C)C(Cl)(Cl)Cl</smiles>

Streptomycin 1952<smiles>CCCCC[C@H](O)/C=C/C1[C@H](C/C=C/CCCC(=O)O)C(=O)C[C@H]1O</smiles>

Prostaglandins (e.g. PGE 2 ) 1982

DDT 1948

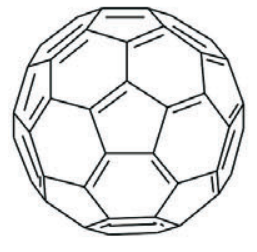

Fullerenes 1996

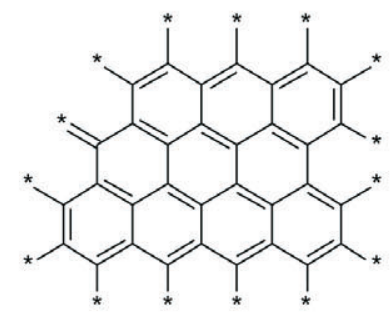

Graphene 2010

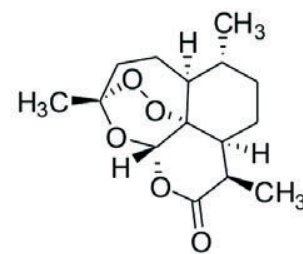

Artemisinin 2015

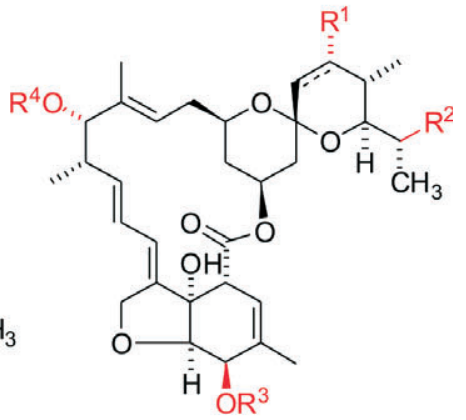

Avermectins 2015

Figure 1 Nobel Prize winning 'Great Molecules'.

economic pursuits. In 2012 the Department of Science and Technology (DST) released the much anticipated committee report on the review of the National System of Innovation (NSI) wherein innovation was broadly defined as 'the capacity to generate, acquire and apply knowledge to advance economic and social purposes'. ${ }^{4}$ Such a definition is intended to encompass research and development, plus education and social marketing of knowledge that might inspire the emergence and growth of small and medium enterprises. The objectives of the NSI are that this type of translation of research should be more socially transformative and sustainable in the long term, so what are the challenges or barriers that have hindered these goals?

From a chemist's perspective it is puzzling why a country that boasts an incredible diversity of flora and fauna does not have 
<smiles>C=C[C@H]1CN2CCC1C[C@H]2[C@H](O)c1ccnc2ccc(OC)cc12</smiles>

Quinine

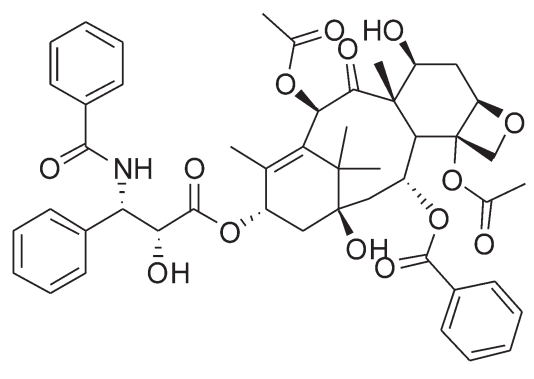

Paclitaxel (Taxol)<smiles>Cc1cn(C2CCNCC2)c(=O)[nH]c1=O</smiles>

Azidothymidine (AZT)<smiles>CC(C)c1c(C(=O)Nc2ccccc2)c(-c2ccccc2)c(-c2ccc(F)cc2)n1CC[C@H](O)C[C@H](O)CC(=O)[O-]</smiles>

Atorvastatin (Lipitor)<smiles></smiles>

Polyhexamethylene adipamide (Nylon 66)<smiles>CCCc1nn(C)c2c(=O)nc(-c3cc(S(=O)(=O)N4CCN(C)CC4)ccc3OCC)[nH]c12</smiles>

Sildenafil (Viagra)<smiles>CNc1ccc(NC(=O)c2ccc(C(=O)C(F)(F)F)cc2)cc1</smiles>

Polyparaphenylene terephthalamide(Kevlar)
Figure 2 Popular 'Great Molecules'.

molecules that feature amongst the world's greatest molecules? After all, South African chemists have access to the warm Indian and frigid Atlantic Oceans and all the assorted marine compounds they harbour, in addition to the incredible geographical landscape that stretches from the tropical north to the temperate southwest and desert-like interior regions of the Karoo and the Northern Cape. While South African botanists have taken advantage of their proximity to the Cape Floral Kingdom, one of the six floral kingdoms of the world, to carve out a position of prestige in world botany, chemists seem to be lagging behind. Michael Davies-Coleman already made a 'call to arms' to all chemists in his article 'Natural Products Research in South Africa: End of an Era on Land or the Beginning of an Endless Opportunity in the Sea?' when he cautioned that 'a perception from current allocation of research funding in SA would suggest that the future of natural products research will increasingly become the responsibility of botanists and ethnobotanists and this new development must be challenged by SA's organic chemists who have been the custodians of natural products chemistry in this country for over a century'. ${ }^{5}$

Even the National Development Plan (NDP), the very ambitious strategic vision for the country in 2030, denunciates South African teachers, supervisors and research investigators for not being sufficiently innovative. Considering that we have one of the oldest world chemical societies (The South African Chemical Society was founded in 1912), is it that South African scientists have not, or are incapable of, discovering great molecules, or is it that we have not been good champions of the molecules we have discovered? Given the long history of natural products, synthetic and medicinal chemistry in the country, it is surprising that there is such low awareness of any 'great molecules' from South Africa.
To start the redress of this state of affairs it seems appropriate to start profiling 'Great South African Molecules' in the South African Journal of Chemistry. The objective is to educate society about the possibilities of how fundamental research is an avenue for entrepreneurs within the bio-economy to counter the persistent perception that a shortage of intellectual capital/capacity is to be blamed for failures in the NSI. What may be lacking is targeted marketing, coordination and incubation of the nascent projects whose long-term nurturing may lie beyond the current management of performance in academia. Thus a concerted effort to spin these ideas in small or medium enterprises is a worthwhile pursuit. Therefore, as part of the response to this challenge, in December 2015 I presented a talk at the National Convention of the South African Chemical Institute (SACI 2015) to profile the first of what I consider is a great South African molecule, a pseudo-disaccharide called mycothiol (1) that is produced by mycobacteria, including one of humanity's greatest nemeses, Mycobacterium tuberculosis (M. tb) (Fig. 3).

Some of the better known South African molecules whose history is well documented include combretastatin (2) which was isolated from the African bush willow of the Eastern Cape

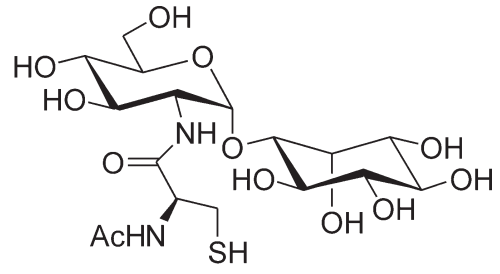

Mycothiol (MSH) 1

Figure 3 Mycothiol. 
(Fig. 4). This compound causes the rapid collapse and necrosis of a tumour's vascular structure and is thus a biologically active antiproliferative since the endothelial cells of tumours are more susceptible to its activity. ${ }^{6}$ A phosphate analogue of combretastatin called fosbretabulin (3) is currently under drug development as an anti-cancer drug (Zybrestat) presumably due to its action as a vascular disruptor agent (VDA).

Among the lesser known compounds which are nonetheless significant in the history of South African molecules is rosmarinine (4), a pyrrolizidine alkaloid whose structure was elucidated by the doyen of South African organic chemistry, Frank Warren, after whom the national meetings of the Organic Chemistry Division of SACI are named. ${ }^{8}$ Other South African compounds of interest include the extremely toxic monofluooacetic acid (MFA) (5) which is the first known natural compound to contain fluorine, ${ }^{9}$ and the guaiane sesquiterpene geigerin (6) which was suspected to be responsible for over 1 million sheep deaths from so-called 'vomiting disease' in the Karoo in the 1930s because it is one of the bitter components found in the Geigeria shrub species. ${ }^{10}$ The real toxic culprit is now thought not to be geigerin, but rather the elusive vermeeric acid precursor of the bis-lactone vermeerin (7). ${ }^{11}$ Lastly, a discussion of famous South African molecules cannot exclude the mycotoxins even though these are not 'a molecule', but rather a diverse group (>300) of fungitoxic compounds including the aflatoxins (8-12) and fumonisins (13, 14). These compounds are produced by fungi that spoil postharvest maize and wheat grain in storage; many South African chemists working primarily out of the Council for Scientific and Industrial Research (CSIR), including Pieter Steyn, Robert Vleggaar and Fanie van Heerden, were very active in the 1980s on investigations of the isolation and biosynthesis of mycotoxins. ${ }^{12}$

So which contemporary compounds deserve to join the list of celebrated South African molecules? There will obviously be dispute, contestation and disagreement about what qualifies a molecule to be classified as South African and why it should be considered great if it is not yet an economic powerhouse or indeed a Nobel Prize winner. As to what qualifies a molecule to be South African, this will be easier to resolve if we set the follow-<smiles>COc1cc(/C=C\c2cc(OC)c(OC)c(OC)c2)ccc1O</smiles>

Combretastatin 2<smiles>O=C(O)CF</smiles>

Monofluoroacetic acid (MFA) 5<smiles>COc1cc(/C=C\c2cc(OC)c(OC)c(OC)c2)ccc1OP(C)(=O)O</smiles>

Forsbretabulin 3<smiles>CC1=C2[C@H](O)[C@H]3[C@H](C)C(=O)O[C@@H]3C[C@H](C)[C@@]2(C)CC1=O</smiles>

Geigerin 6<smiles>C/C=C(/C[C@H](C)[C@@](C)(O)C(=O)OC[C@H]1[C@H](O)CN2CC[C@H](O)[C@@H]12)C(=O)O</smiles>

Rosmarinine 4<smiles>C=C1C(=O)OC2CC(C)C3CC(=O)OC[C@]3(C)CCC12</smiles>

Vermeerin 7<smiles></smiles>

$\mathrm{R}=\mathrm{H} \quad$ Aflatoxins $\mathrm{B}_{1}$ 8; $\mathrm{B}_{2}$ (8,9-dihydro) 9 $\mathrm{R}=\mathrm{OH}$ Aflatoxin $\mathrm{M}_{1} 10$<smiles>COc1cc2c(c3oc(=O)c4c(c13)CCOC4=O)C1C=C[CH]C1O2</smiles>

Aflatoxins $\mathrm{G}_{1} 11 ; \mathrm{G}_{2}$ (8,9-dihydro) 12<smiles>[R]C(CCCC[C@H](O)C[C@H](O)[C@H](C)N)C[C@@H](C)C[C@@H](OC(=O)C[C@@H](CC(=O)O)C(=O)O)[C@@H](OC(=O)C[C@H](CC(=O)O)C(=O)O)[C@@H](C)CCCC</smiles>

$\mathrm{R}=\mathrm{H} \quad$ Fumonisin $\mathrm{B}_{1} 13$

$\mathrm{R}=\mathrm{OH}$ Fumonisin $\mathrm{B}_{2} 14$

Figure 4 South African molecules with a celebrated history. 
ing two reasonable restrictions, that a compound is or may be considered to be South African if:

- it was discovered by scientist(s) working in a South African university, research institute or company; this will be the default definition of a South African researcher, not necessarily immigration or citizenship status.

- South African researchers are at the forefront of highlighting the significance of the molecule, even if they were not the initial discoverers.

As to what qualifies a non-Nobel Prize winning or blockbuster molecule to 'greatness' will always be a topic of great discussion, but a molecule could be classified as great if it has a scientific impact and is well-known and researched. This may be indicated by the number of publications, citations, h-index, or even that the molecule has a common or trivial name. For example, the $h$-index is a factor that seeks to gauge the long-term value of a topic based not only on how well cited that topic might be, but also how well cited are those doing the citation. ${ }^{13}$ Thus a high h-index value suggests that the topic is highly valued by other scientists whose work is also well regarded by other scientists.

The most important criterion, however, should be the potential and scope for continued and further investigation of the utility of the compound. This point is important to generate local research or commercial interest in the molecule, which might in turn stimulate economic activity or has the capacity of generating translation that addresses the needs of the society. While it might be true that molecules may have some inherent potential for greatness, that potential can only be unlocked by scientists exploring, reporting and exploiting the knowledge embedded in the molecule and its properties. Therefore, it should not just be a matter of whether a molecule exceeds some minimum threshold metrics, but advocates of the molecule must make an argument to justify the research capacity of the molecule. Ideally this case should be subjected to peer and public scrutiny via publication in the South African Journal of Chemistry.

\section{Is Mycothiol a Great Molecule?}

Does mycothiol qualify for consideration as a great molecule? To be transparent in this evaluation, mycothiol is compared to the other well-known South African compounds as shown in Table 1. To further illustrate the reasonableness of the criteria, Table 1 also includes a few international 'great molecules' for comparison. While the international molecules all have superior metrics (Table 1, entries 8-12), some of the well-known South
African molecules like MFA (Table 1, entry 1), geigerin (Table 1, entry 2 ) and rosmarinine (Table 1 , entry 3 ) have very low publication and citation metrics. However, fosbretabulin (Table 1, entry 4), combretastatin (Table 1, entry 5) and mycothiol (Table 1, entry 7) have reasonable publication presence to be considered as great molecules, thus there is little dispute that mycothiol passes the first hurdle. Therefore we may proceed to the determination of whether the molecule is South African, before delving into its potential for further research or societal impact.

\subsection{Is Mycothiol a South African Molecule?}

Mycothiol is a low-molecular-weight thiol (LMWT) weighing only $486.49 \mathrm{~g} \mathrm{~mol}^{-1}$ with a molecular formula of $\mathrm{C}_{17} \mathrm{H}_{30} \mathrm{~N}_{2} \mathrm{O}_{12} \mathrm{~S}$. It was first discovered, but not characterized, by Robert Fahey and Gerald Newton and their group at the University of California San Diego (UCSD, USA) as the 'surprisingly previously unknown thiol' present as the majority thiol in their study of 'low-molecular-weight thiols in streptomycetes and their potential role as antioxidants'. ${ }^{14}$ While acknowledging the discovery of U17 (unknown thiol eluting at 17 minutes) as a potential antioxidant, they concluded their report with the prophetic words that 'the first step in testing the protective role of U17 is to fully elucidate its structure and studies to achieve this goal are in progress ${ }^{\prime}{ }^{14}$ This paper was accepted on 23 February 1993 (submitted on 26 October 1992) while across both the Atlantic and Pacific oceans two other research groups were independently also hot on the trail of this thiol. Yasuhiro Yamada and his co-workers at Osaka University (Japan) were investigating the biosynthetic pathway towards allosamidin (15) which was the first known chitinase inhibitor produced by streptomycetes sp..$^{15}$ (Fig. 5). In 1994 they published their report (submitted on 4 February 1994) on the structure of a dimeric disulfide metabolite found in the mycelial extracts of streptomycetes whose monomer was determined to be 2 - $(N$-acetyl-L-cysteinyl)amido-2-deoxy- $\alpha$-D-glucopyranosyl-( $1 \rightarrow 1)-1 \mathrm{D}$-myo-inositol $(\mathbf{1}){ }^{16}$

At the same time Daniel Steenkamp was working in chemical pathology at the University of Cape Town (South Africa) investigating the 'thiols of intracellular pathogens' focussing on the protozoa, especially the Leishmania species. After having confirmed that ovothiol A (16) is indeed produced by Leishmania donovani which causes visceral leishmaniases (Fig. 5), Steenkamp decided to 'isolate and perform a structural analysis' of any of the then uncharacterized thiols produced by Gram-positive bacteria. The choice of Mycobacterium bovis BCG which was moti-

Table 1 Comparison of the publication metrics of molecules.

\begin{tabular}{|c|c|c|c|c|c|}
\hline Entry & Compound name & SciFinder ${ }^{a}$ & Publications ${ }^{\mathrm{b}}$ & Citations $^{c}$ & H-Index ${ }^{c}$ \\
\hline 1 & Monofluoroacetic acid (MFA) & 1593 & 49 & 811 & 15 \\
\hline 2 & Geigerin & 33 & 6 & 58 & 3 \\
\hline 3 & Rosmarinine & 58 & 13 & 184 & 8 \\
\hline 4 & Fosbretabulin & 639 & 430 & 19600 & 73 \\
\hline 5 & Combretastatin & 2475 & 1768 & 51053 & 101 \\
\hline 6 & Mycotoxins & 43720 & 24106 & $X^{d}$ & $X^{d}$ \\
\hline 7 & Mycothiol (MSH) & 488 & 650 & 7921 & 49 \\
\hline 8 & Sildenafil (Viagra) & 11879 & 20551 & $X^{d}$ & $X^{d}$ \\
\hline 9 & Atorvastatin (Lipitor) & 20736 & 28417 & $X^{d}$ & $X^{d}$ \\
\hline 10 & Paclitaxel (Taxol) & 67274 & 90368 & $x^{d}$ & $X^{d}$ \\
\hline 11 & Artemisinin & 10587 & 16436 & $X^{d}$ & $X^{d}$ \\
\hline 12 & Avermectins & 5176 & 1223 & 25401 & 70 \\
\hline
\end{tabular}

a As of June 11, 2016; references found that contain the concept of the topic

${ }^{b}$ As of June 11, 2016; from the 'results found' in the Web of Science topic search for the period 1950-2016

${ }^{c}$ As of June 11, 2016; from the Web of Science citation report for the period 1950-2016

${ }^{\mathrm{d}}$ Web of Science cannot generate a citation report if the search question produces $>10000$ results (publications), hence the value is unknown $(\mathrm{X})$ or not available. 


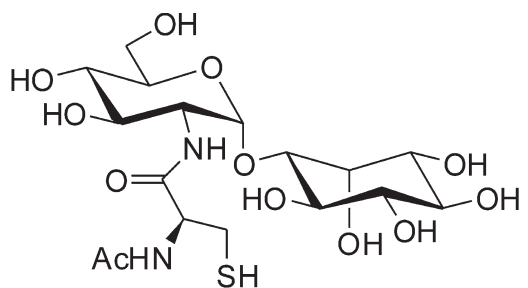

Mycothiol (MSH) 1

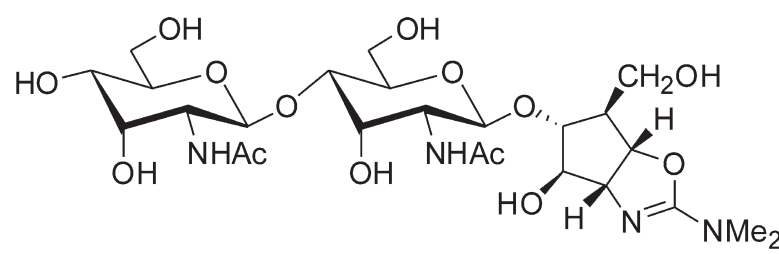

Allosamidin 15<smiles>Cn1cnc(S)c1CC([NH-])C(=O)[O-]</smiles>

Ovothiol A 16<smiles>C[N+](C)C(Cc1cnc(S)[nH]1)C(=O)O</smiles>

Ergothioneine (ESH) 17<smiles>N[C@@H](CS)C(=O)N[C@H](OC1C(O)C(O)C(O)C1CO)[C@H](CC(=O)O)C(=O)O</smiles>

Ergothioneine $(\mathrm{ESH}) \mathbf{1 8}$

Figure 5 Allosamidin and low molecular weight antioxidant thiols of intracellular pathogens.

vated in part by its close genetic relationship to pathogenic mycobacteria, namely Mycobacterium tuberculosis (M. tb), proved fortuitous because the isolated major thiol was structurally determined to be none other than 1! Steenkamp and Hendrik Spies (University of Stellenbosch, South Africa) who performed the NMR structural elucidation, coined the name mycothiol for this cysteinyl pseudo-disaccharide and published their report in 1994 (submitted on 15 April 1994). ${ }^{17}$ In their article Spies and Steenkamp speculated that the unknown thiol U17 discovered by Newton et al. the previous year could be mycothiol and this was later confirmed in a follow-up paper by the UCSD group published in 1995 (submitted on 27 December 1994). ${ }^{18}$ In 1996 the abbreviation MSH for mycothiol was proposed by Robert Fahey's group in their seminal paper on the distribution of thiols in microorganisms which confirmed that MSH is the major thiol in the actinomycetes. ${ }^{19}$

Thus, while Spies and Steenkamp may not have been the first to discover mycothiol, along with Yamada's group they simultaneously proposed a structure of this thiol and indeed it was they who first proposed the common name for the molecule. Significantly, as the name suggests, Spies and Steenkamp were the first to indelibly link this compound to mycobacteria and by extension to $M$. $t b$, which subsequently opened up a very vibrant and diverse research enterprise because of the significance of $M$. $t b$. It is therefore justified to claim MSH as a South African molecule.

To further emphasize the critical link to South Africa, Steenkamp and co-workers were the pioneers in investigation and elucidation of the biosynthesis of $\mathrm{MSH}^{20}{ }^{20}$ but given the smaller number of researchers in South Africa working on the topic, faster progress was made elsewhere. The elucidated biosynthetic pathway to date is shown in Scheme 1. This is the composite picture from the efforts of a diverse group of researchers, but the central role of Fahey and his collaborators in the USA and Canada is unmistakable. ${ }^{21}$ Several informative reviews have been written that highlight the identification, isolation, mechanisms and biochemistry of MSH biosynthesis. ${ }^{22}$

\section{Why is Mycothiol a Molecule of Great Potential?}

Since we have established that mycothiol is a South African molecule that surpasses the minimum requirements for greatness, as the advocate for the molecule I will now discuss its virtues as to the potential that exists for further investigation to sustain local research interest in its utility and capacity for the development of commercial outputs as part of research translation to address the needs of the South African society.

\subsection{Mycothiol's Significance to the TB Problem}

Quite obviously due its association with $M$. $t b, \mathrm{MSH}$ has a significant potential role as a druggable target in the development of new treatments to alleviate the dread and burden of tuberculosis disease (TB). In the contemporary South Africa envisioned in the NDP, the most important aspect to investing in MSH research would be its potential to address a key South African or African societal need which is particularly urgent for a Third World country at the confluence of an increasing burden of First World 'lifestyle' diseases like hypertension, cardiovascular and diabetes, with the Third World threats of TB and $\mathrm{HIV}^{23}$

MSH plays a role in the self-defensive antioxidant response of mycobacteria to an elevated oxidative intracellular environment, ${ }^{24}$ and also a part in the detoxification mechanism of xenobiotics. Thus MSH is a druggable target in the search and development of drugs against TB, particularly new drugs to counter bacterial resistance against the current therapies. ${ }^{21,24-25}$ The need for new antitubecular drugs, even from the semi-synthetic derivatizations of naturally occurring products has recently been highlighted as part of the urgency in the search for new treatments. ${ }^{26}$ There is an urgent need to develop more efficacious treatments against a disease that affects over 9 million people per year worldwide and is the second deadliest by a single infectious agent, trailing only HIV with which it most often occurs as a co-infection. ${ }^{27}$ For a country like South Africa where the public primary healthcare infrastructure is weak the problem is exacerbated by haphazard compliance with the current lengthy TB treatment regimens leading to the development of drug resistance, ${ }^{28}$ including the emergence of multiple and extensively drug-resistant $M$. tb strains (MDR and XDR, respectively) and even some totally drug-resistant (TDR) forms of the disease. ${ }^{26 e, 29}$

\subsubsection{Mycothiol as an Antioxidant and a Co-factor}

MSH chemistry provides a research opportunity for the search of new treatments based on the complex biochemistry of this 


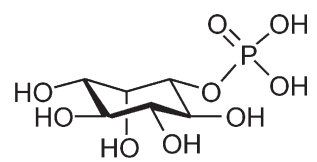

Ins-P

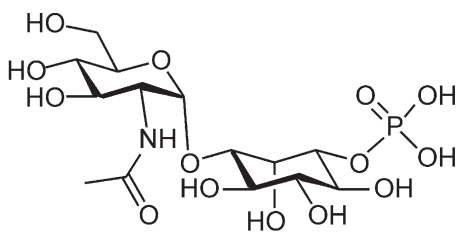

GIcNAc-Ins-P
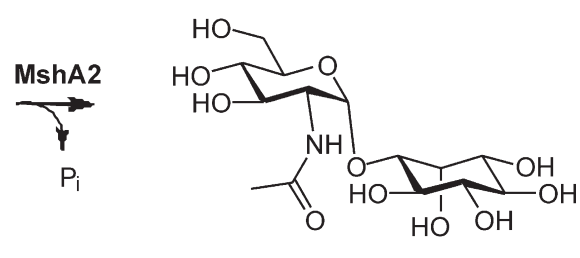

GIcNAc-Ins

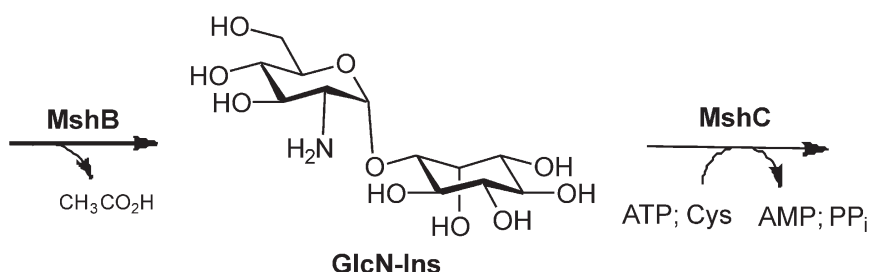

GIcN-Ins

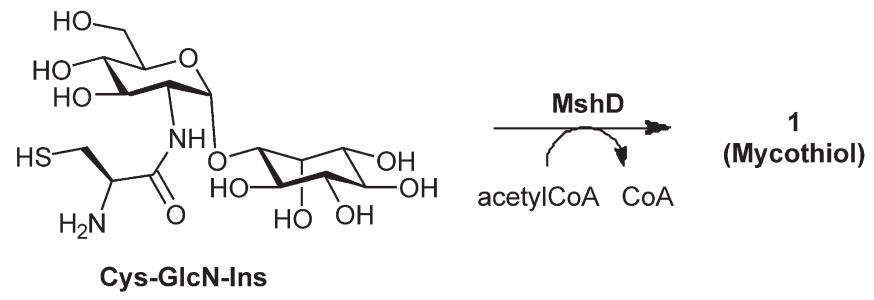

Scheme 1

Biosynthetic pathway to mycothiol. molecule. While the enzymes involved in MSH biosynthesis have been identified, many aspects of the role of MSH are incomplete and are still open for further exploration. ${ }^{21,22 a, 22 c}$ These include understanding the specific mechanism of MSH's role as an antioxidant because it has been established that MSH is more resistant to auto oxidation compared to glutathione and cysteine ${ }^{30}$ and that MSH-deficient mutants of $M$. smegmatis have been shown to be hypersensitive to oxidative stress. ${ }^{24,31}$ However, MSH deficiency seemed to imbue mutants with resistance to the commonly used first-line bactericidal drug isoniazid, yet it has also been reported that vitamin $C$ is a very effective mycobactericidal antioxidant, even against MDR strains. ${ }^{28}$ It therefore seems likely that the development of MSH-inhibiting drugs used in combination with vitamin $\mathrm{C}$ could be the basis of a new treatment for TB.

To further highlight its potential as a target in the development of antibiotics against TB, MSH has also been demonstrated to enhance the activity of other antibiotics like rifampin, ${ }^{25 \mathrm{c}}$ or that it acts as an oxidant resistant reservoir of cysteine, ${ }^{32}$ or in general as a co-factor for other detoxification and antioxidant systems..$^{33}$ Given the recent reigniting of interest in MSH biosynthesis it is quite evident that plenty of opportunities are available for local chemists and biochemists to play their role.

\subsubsection{Mycothiol Analogues as Potential Biosynthetic Targets}

There have been a few reports on the chemical synthesis of MSH and its intermediates going back to the first total synthesis by Steenkamp and co-workers in 2002, up to the most recent efforts to improve glycosylation stereochemistry via endocyclic cleavage anomerization of $\beta$-glycosides to $\alpha$-glycosides reported by Manabe and Ito. ${ }^{34}$ These reports highlight how $\mathrm{MSH}$ is not only a medicinal target, but also that since it is a formidable synthetic challenge there are opportunities for further research by carbohydrate and synthetic chemists. It is reasonable to hypothesize that competitive substrate inhibition of the biosynthesis of MSH could also be a gateway to possible antitubecular drug targets. ${ }^{35}$

Thus the synthesis of MSH analogues has been a vibrant area of research in the last 22 years. David Gammon and his co-workers at the University of Cape Town (South Africa) have sustained the local interest in this area (Fig. 6). ${ }^{36}$ Several MSH analogues, especially the conjugates of plumbagin 21a-21d have shown promising inhibitory activity and good binding specificity to some of the enzymes involved in mycobacterial self-defence.
In the spirit of continuing to mine this local resource, our group at the Tshwane University of Technology (Pretoria, South Africa) is also actively involved in the pursuit of 'mycothiol chemistry' as part of our programme on tuberculosis and cancer research. ${ }^{37}$

Other groups that have been very active in the synthesis and biological evaluation of MSH analogues include Spencer Knapp at Rutgers University (New Jersey, USA) ${ }^{38}$ and Carol Bewley at the National Institutes of Health (NIH) (Maryland, USA). ${ }^{39}$ Two compounds that have shown promising biological activity from the large libraries which have been screened by these groups are shown in Fig. 7. The Knapp-inspired compound 27 was found to be a very good substrate inhibitor of the deacetylase enzymes MshB and $\mathrm{Mca}^{39 \mathrm{~d}}$ while compound 28 showed moderate inhibition of MshC, but surprisingly results in a $60 \%$ decline in the production of MSH at only $30 \mu \mathrm{M}$ and a $99 \%$ loss of viability of non-replicating cultures of $M$. tb at $90 \mu \mathrm{M}^{21 \mathrm{c}, 40}$

Since South Africa has limited resources and a smaller critical mass of researchers, it makes reasonable sense for local chemists to scavenge information about promising lead compounds from the literature for further derivatization and 'molecular editing' to enhance the efficacy of these molecules. The experience of the Chinese in their search for an anti-malarial candidate in the 1960s, leading to the discovery of artemisinin, should be a model for South Africa in scouring the literature about what is already known and how we could exploit that resource pool. Project 523 was a Chinese government initiative began in 1967 to expeditiously find a treatment for chloroquine resistant Plasmodium falciparum to aid their North Vietnamese allies who were now battling both the Americans and malaria. ${ }^{41}$ Over 500 scientists and 60 laboratories were recruited for the initiative and by 1969 three treatments were available. The discovery of artemisinin by 1971, following an investigation of over 2000 traditional herbal recipes, was eventually recognized with a share of the Physiology or Medicine Nobel Prize in 2015 for the group leader Youyou $\mathrm{Tu}$. The lesson for us in South Africa and Africa in general it should be emphasized, must be that a painstaking evaluation and modification of what is already known may open the door to great treasures just beneath the surface. I think that MSH chemistry possesses such a potential to be exploited.

\subsubsection{Mycothiol Analogues as Trojan Carriers}

A recent exciting development in mycothiol chemistry is the exploitation of the promiscuous activity of MSH enzymes, espe- 


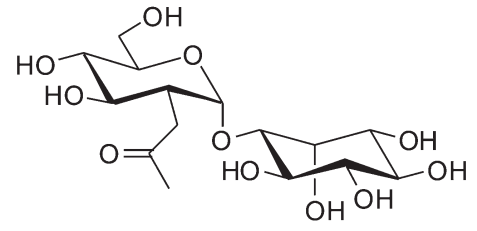

19

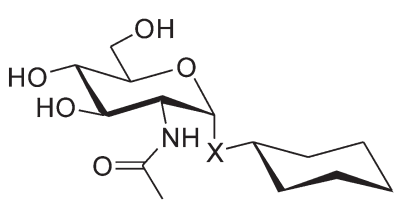

$22 x=0$

$23 x=S$

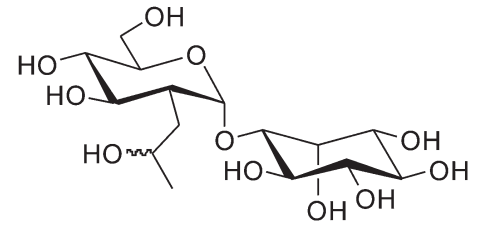

20

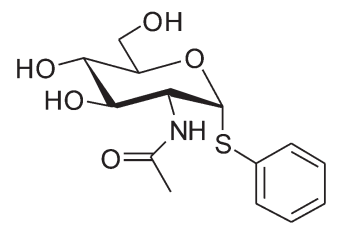

24

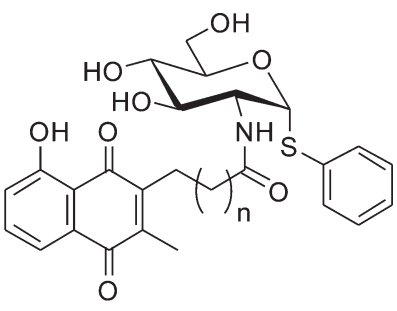

$21 a-21 d(n=2-5)$

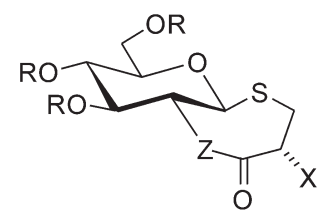

25a $X=N H A c ; Z=O$

25b $X=N H A c ; Z=N H$

26a $\quad X=H ; \quad Z=O$

26b $\quad X=H ; \quad Z=N H$

Figure 6 Substrate analogues of mycothiol synthesized in South African laboratories.

cially the deacetylases MshB and Mca. For example, TeesdaleSpittle and co-workers (New Zealand) reported how benign mycothiol conjugate analogues (29) could be used to smuggle pro-reactive electrophiles 33 into the intracellular space where a toxic mercapturic species is generated via a cascade of reactions initiated by the action of MshB or Mca in the deacetylation/detoxification of cysteinyl S-conjugates ${ }^{42}$ (Scheme 3), In this work the mycothiol analogues are proposed to be progenitors of a new generation of anticancer cytotoxic agents. This is a wonderful expansion of the possible scope of work arising from the deepening exploration of MSH chemistry which bodes well for the growing stature of this molecule.

Similarly, Janata and co-workers (Czech Republic) have shown that the action of MshB and Mca triggers a downstream production of lincosamide antibiotics, with the potential to expedite the synthesis of new libraries of analogues of the natural antibiotics. ${ }^{43}$ Compound 34 is a mycothiol S-conjugation electrophilic adduct formed from 4-propyl-L-proline, an octose amino sugar and ergothioneine which reacts with MSH to form an S-conjugate (35) that is 'detoxified' by Mca. However, the excreted mercapturic acid 36 can be consumed by the lincomycin biosynthesis pathway to form the antibiotic lincomycin (37) (Scheme 4). In their concluding remarks these authors highlighted how finding that a key detoxification step in one process can be switched seamlessly towards a biosynthetic mode in another process bodes well for more exciting research in this area. I concur and that is why a key objective of this article is to churn the interest of

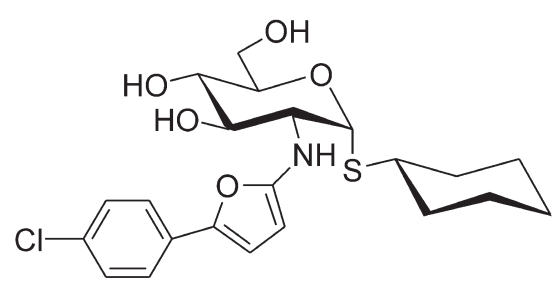

$$
\begin{aligned}
27 I_{50} & =7 \mu \mathrm{M} \text { for MshB } \\
I C_{50} & =33 \mu \mathrm{M} \text { for Mca }
\end{aligned}
$$

South African chemists to explore more aspects of MSH chemistry!

Lastly, a very interesting approach to the 'hijacking' of MSH biosynthetic enzymes comes from Padhye and co-workers (India) who have linked the results on how plumbagin analogues inhibit MshB activity by Gammon et al. to conjugate plumbagin to isoniazid to form a synergistic attack on the bacterial defences. ${ }^{36 c, 44}$ The plumbagin-isoniazid analogue 39 (Fig. 8) showed promising inhibition even at low iron concentrations; this was a significant result because it implied that the mode of action of the new compound bypassed the mechanism of resistance to isoniazid which is inactive at low iron concentration. So while MSH-deficient mutants are more resilient to isoniazid, ${ }^{25 a}$ when MshB is selectively inhibited there is a decline in resistance and an enhancement of the isoniazid activity.

This reaffirms that there are many opportunities to explore for MSH chemistry, especially in the area of combination of natural products and other compounds of known bacteriostatic or bacteriacidal activity. ${ }^{45}$

3.2. Mycothiol Synthesis as a Synthetic Methodology Challenge A significant challenge in MSH chemistry which is yet to be fully resolved is a simplified method for Gram-scale synthesis of MSH. Thus the synthesis of MSH has been a 'proving ground' for carbohydrate chemists and methodology gurus and junkies alike. Twenty two (22) years after its discovery, there are still new reports on attempts to improve the total synthesis of $\mathrm{MSH}^{34,, 34 \mathrm{f}}$<smiles>CN(CCCNC(=O)c1ccc2c(c1)N(Cc1cccc(Cl)c1)C(=O)c1ccccc1S2=O)C1CCCCC1</smiles>

$28 \mathrm{IC}_{50}=100 \mu \mathrm{M}$ for MshC

Figure 7 Substrate inhibitors of mycothiol biosynthesis. 


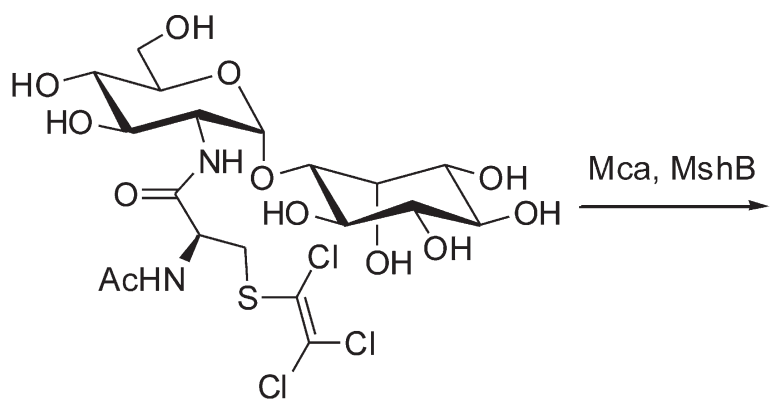

29<smiles>N[C@@H](CSC(Cl)=C(Cl)Cl)C(=O)O</smiles>

30

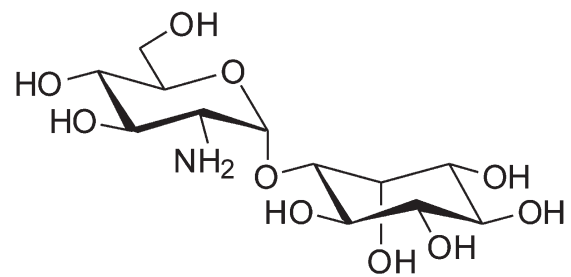

GlcN-Ins 31 $\beta$-lyase<smiles>CC(=O)C(=O)O</smiles>

32<smiles>C=C[Hg]</smiles><smiles>S=C(Cl)C(Cl)Cl</smiles><smiles>C1=CC=C1</smiles><smiles>S=C=C(Cl)Cl</smiles>

33

Scheme 3

Mycothiol as a Trojan carrier.

The molecule is deceptively simple comprising as it does of only three subunits, a D-myo-inositol that is glycosidically linked to a D-glucosamine whose amine is acetylated by $\mathrm{N}$-acetyl cysteine. We recently wrote a comprehensive review on the advances made over the last five years in overcoming some of the synthetic challenges ${ }^{46}$ The two paramount challenges are firstly, the desymmetrization and regioselective protection of myo-inositol and secondly, the stereoselective glycosylation to give a 1,2-cis-glycoside. Both of these are non-trivial synthetic challenges that have led to some of the most creative and ingenious solutions.

So far the most efficient method for the regioselective protection of myo-inositol for application to the synthesis of $\mathrm{C} 1$ glycosylated derivatives is due the work of Shashidhar (India) and co-workers to make myo-inositol-1,3,5-orthoformate 40 (the so called Kishi's triol) which is now also commercially available. ${ }^{47}$ This orthoformate can easily be regioselectively derivatized to give the meso diol 44. Shang-Cheng Hung (Taiwan) has shown that this diol can readily and efficiently be desymmetrized by reaction with a chiral ketopinyl ester as the chiral derivatizing agent to give the appropriately protected myo-inositol (45) as shown in Scheme $5 .^{48}$ Other research groups in Australia, the UK and Sweden have also contributed creative solutions to myoinositol resolution and regioselective protection, including<smiles>NNC(=O)c1ccncc1</smiles><smiles>CC1=CC(=NNC(=O)c2ccncc2)c2c(O)cccc2C1=O</smiles>

Isoniazid 38

Figure 8 Isoniazid and its plumbagin conjugate.<smiles>CCCC1CN[C@H](C(=O)N[C@H]2C(O)C(O)C(O)C(O)C(Sc3ncc(C[C@H](C)N(C)C)[nH]3)C2O)C1</smiles>

34
MSH toxin conjugation<smiles>CCCCCC</smiles>

ergothioneine

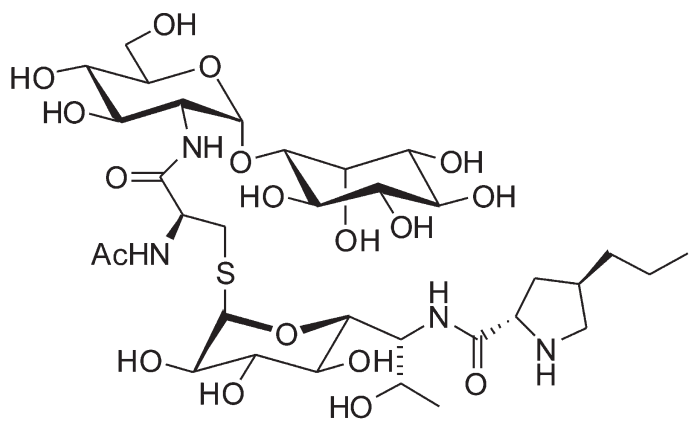

35

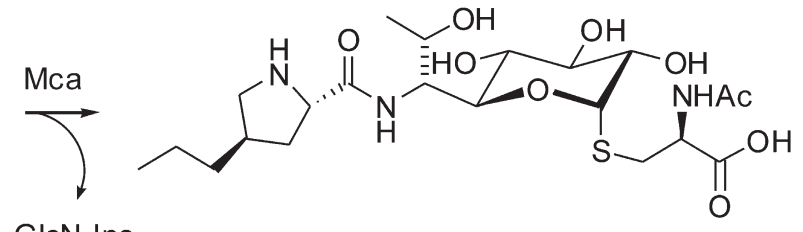

GlcN-Ins

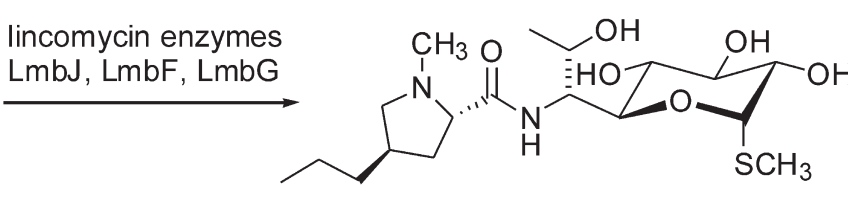

lincomycin 37

Scheme 4

Harnessing mycothiol detoxification mechanism for antibiotic synthesis. 


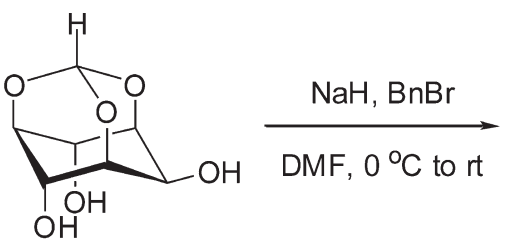

40

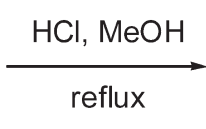

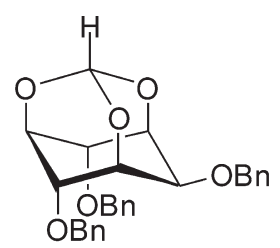

$4150 \%$
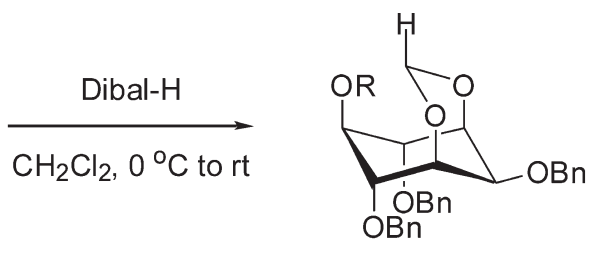

$42 \mathrm{R}=\mathrm{H}(96 \%)$

$43 \mathrm{R}=\mathrm{Bn}(93 \%)$

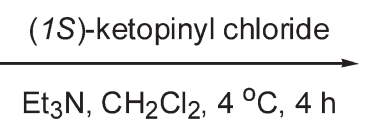

Scheme 5

Regioselective desymmetrization of myo-inositol.

camphor acetal dynamic resolution of fully unprotected myoinositol, to the regioselective protection induced by acyl migration. ${ }^{37 a, 49}$

A well-known dilemma in carbohydrate chemistry is that of poor diastereoselectivity to form 1,2-cis-glycosides during a glycosylation. Functional groups at $\mathrm{C} 2$ of a glycosyl donor capable of stabilizing the oxocarbenium ion intermediate via resonance electron donation generally lead to high diastereoselectivity for 1,2-trans-glycosides. However, the conditions for the synthesis of highly diastereoselective 1,2-cis-glycosides are not common or routine. A significant development in stereoselective glycosylation chemistry was made a quarter century ago when the idea of matched/mismatched donors and acceptors based on the armed or disarmed reactivity of glycosyl donors was proposed by Fraser-Reid. ${ }^{50}$ Fraser-Reid demonstrated for the first time that competitive glycosylation between armed and disarmed donors could be chemoselective with an armed donor reacting preferentially to give a mixture of glycosides $(\alpha / \beta 2: 1)$ while a disarmed donor would remain unreactive. Subsequently other groups have expanded on this concept to show that armed/disarmed reactivity could be modulated to achieve stereoselectivity in the glycosylation reaction..$^{51}$

There have been many fascinating approaches in the quest for 1,2-cis-glycosides, including remote group assistance or directing effects from protecting groups at either C3, C4 or C6 of the glycosyl donors. ${ }^{51 e, 52}$ However, the most creative innovation has come from a variation of the armed/disarmed control of glycosylation stereochemistry that has been used by the Hien Nguyen (Iowa, USA) and Spencer Knapp (New Jersey, USA). These groups have adapted a form of native chemical ligation where the aglycon is tethered or closely associated with the reactive donor intermediate such that there is an intramolecular aglycon transfer (IAT). Such a transfer can thus only come from one face of the donor. In the Nguyen approach an N-benzylidene protection on a glucosamine donor (46) with an $N$-phenyltrifluoroacetimidoyl leaving group mimics an intramolecular 'trapping and transfer' of the aglycon, preferentially from the $\alpha$-face of the molecule to give the 1,2-cis-glycoside 47 (Scheme 6). ${ }^{53}$ Indeed, complete glycosylation diastereoselectivity was observed with minor modification of the donor as shown in Scheme 7.

Knapp and co-workers elegantly adapted the IAT tactic by tethering the acceptor to the donor and that it adds to the reactive oxocarbenium ion from only one face of the molecule to achieve the stereoselective $\alpha$-glucosaminidation (Scheme 8). ${ }^{34 \mathrm{~g}}$
The glycosyl sulfide donor $\mathbf{5 3}$, which is an $\mathrm{N}$-arylsulfonamide, was alkylated by a suitably protected myo-inosityl acceptor 56 which was formed in situ from the methylthiomethyl ether 55 . The phenylsulfenyl chloride activation of the glycosyl sulfide, in the presence of catalytic AgOTf gave the AAA-stereoselective glycosylation in $93 \%$ yield. The subsequent deprotection steps of 58 to give $\alpha$-GlcN-Ins (29) are straightforward and therefore recommends this intramolecular aglycon transfer method as one of the preferred routes for the synthesis of 1,2-cis glucosamine glycosides.

Overall then, the challenge of synthesizing MSH has led to the development of new strategies to address a generic problem in glycosylation chemistry.

\subsection{Mycothiol Monitoring and Bioassays}

Finally, the last class of opportunities that arises out of MSH chemistry which I wish to highlight is the need for the development of faster, more accurate and specific bioassays to accelerate the search for new antitubecular agents. As early as 1998 Fahey and co-workers emphasized the need for a sensitive and specific immunoassay for MSH as part of screening for infections by the actinomycetes and $M . t b$ in particular. ${ }^{54}$ The current method to confirm $M$. $t b$ infection by culturing sputum is uneconomical with respect to duration and also in that it requires sophisticated infrastructure for the safety and expertise to grow cultures of $M$. $t b$. An ELISA (enzyme-linked immunosorbent assay) microtitre plate test or a readable strip would result in time and expense savings and more importantly widespread testing at the primary health care facilities, before communicable infections spread. This remains an open challenge for South African chemists to develop affordable assays for use in this country.

Meanwhile Julie Leary and co-workers at the University of California Davis (USA) reported on a mass spectrometric method for the analysis (identification and quantification) of MSH that uses minimal sample preparation and is well suited for laboratories doing MSH biosynthetic inhibition studies. ${ }^{55}$ This method was checked and validated to be a suitable alternative to the traditional HPLC methods of analysis that require the prior $S$-derivatization of MSH with a UV active group; normally bromobimane is the choice derivatizing agent. However, some of the most exciting developments in this area of real-time monitoring of the biosynthetic activity of potential inhibitors have come from Chris Hamilton at the University of East Anglia (UK), ${ }^{56}$ Marcy Hernick at Virginia Tech (USA), ${ }^{57}$ and Anwar Jardine at the University of Cape Town (South Africa) ${ }^{58}$ Interest- 


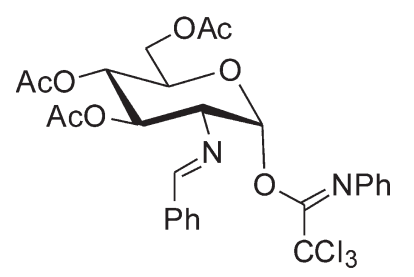

46<smiles>[R]OC1OC(COC(C)=O)C(N=Cc2ccccc2)C(OC(C)=O)C1O[R]</smiles>

47

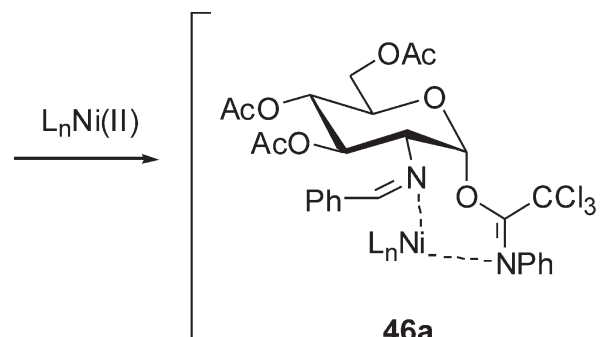

$46 a$

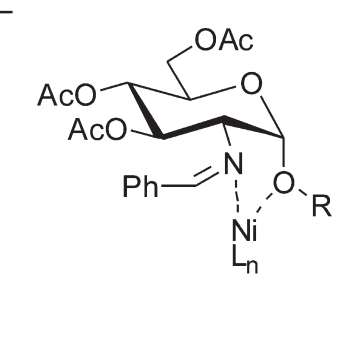

$46 d$

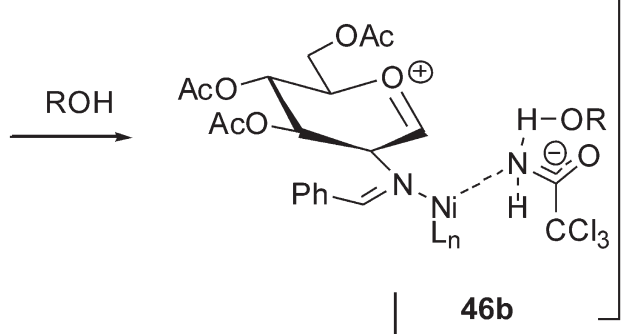

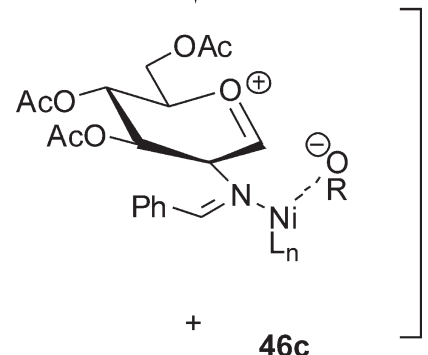<smiles>NC(=O)C(Cl)(Cl)Cl</smiles>

Scheme 6

Mechanistic rationale for nickel catalysed stereoselective glycosylation on $\mathrm{N}$-benzylidene glucosamine donors.

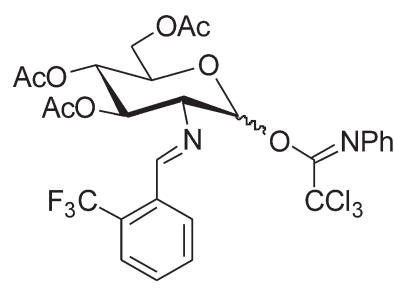

48
$10 \mathrm{~mol} \% \mathrm{Ni}(4-\mathrm{F}-\mathrm{PhCN})_{4}(\mathrm{OTf})_{2}$

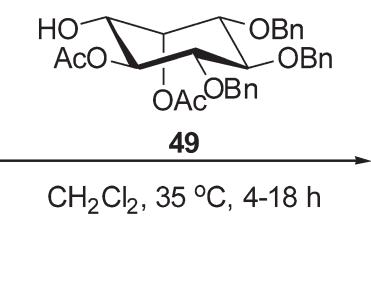

Scheme 7

Complete diastereoselective glycosylation to form D-GlcN-Ins.

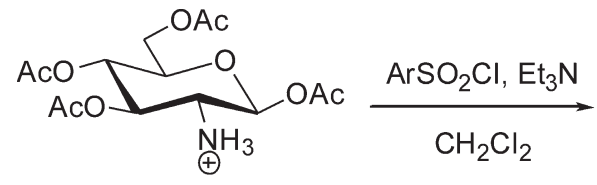

51

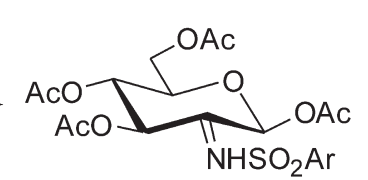

52 95\%

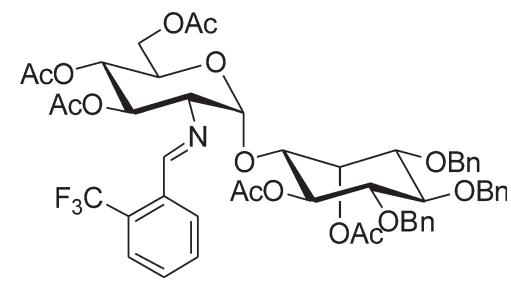

$50 \quad 48-81 \%($ only $\alpha)$

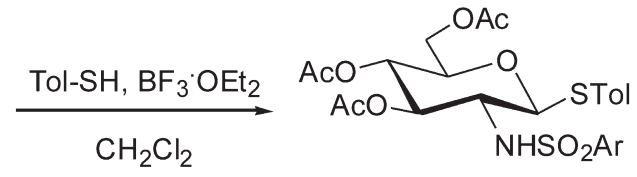

53 93\% $(\alpha / \beta 1: 9)$

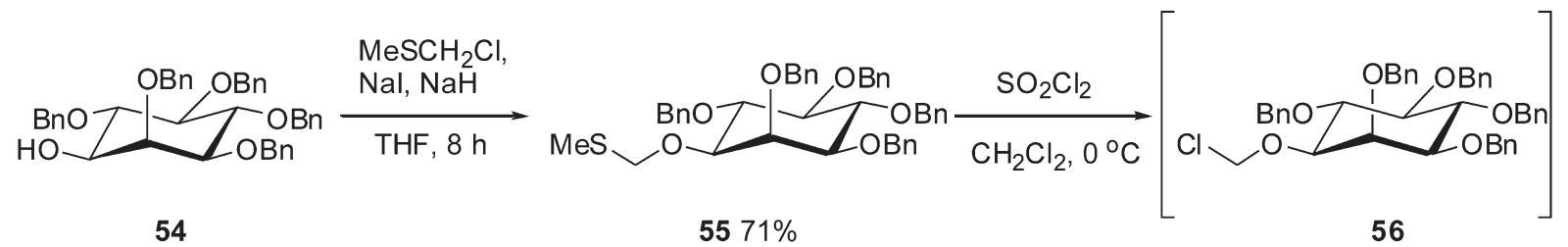

54

$5571 \%$

56

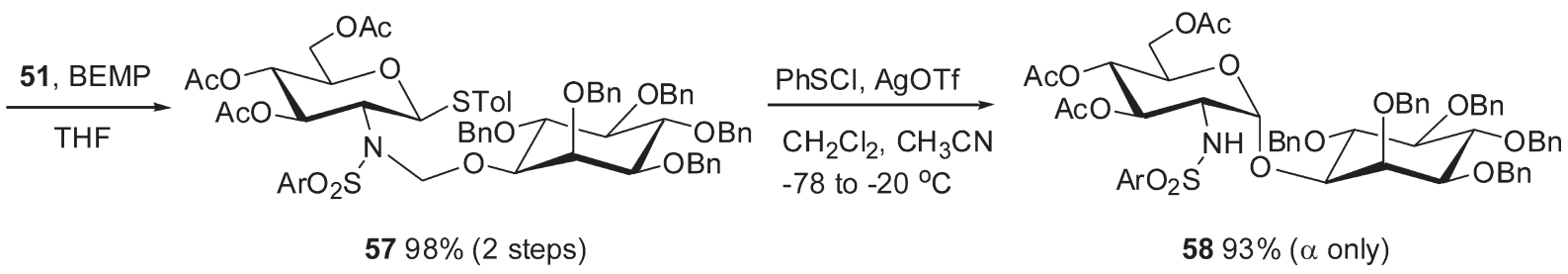

Scheme 8

Intramolecular aglycon transfer in 1,2-cis-glycosylation. 


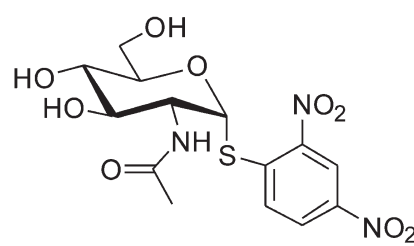

59

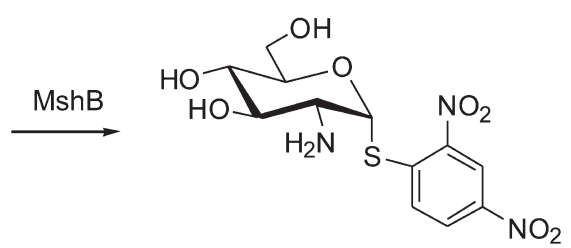

60

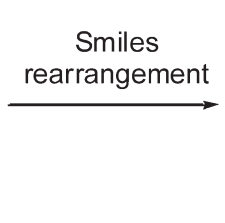

61
$\mathrm{NO}_{2}$

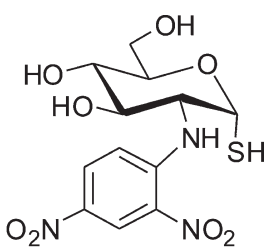

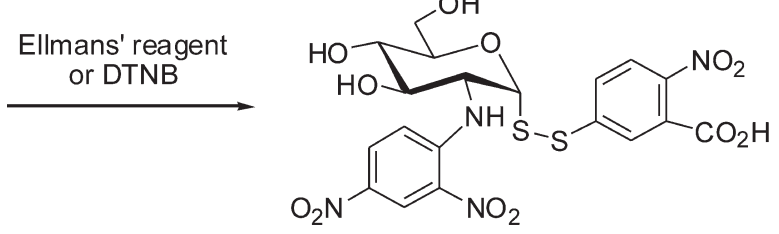

62

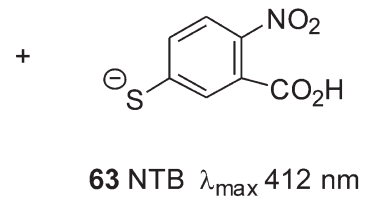

63 NTB $\lambda_{\max } 412 \mathrm{~nm}$

Scheme 9

Serendipitous discovery of a MshB activity assay via a Smiles rearrangement.

ingly, while the Hamilton and Hernick groups specifically set out to demonstrate new assays to monitor the mycothiol disulphide reductase (Mtr) and MshB enzymes respectively, Jardine and co-workers discovered a new assay for MshB by sheer serendipity (Scheme 9). When compound 59 which is a good substrate for MshB was exposed to this enzyme, $\mathrm{N}$-deacetylation ensued followed by a spontaneous Smiles rearrangement to give $N$-aryl glycosylsulfide $\mathbf{6 1}$, which on reaction with Ellmans' reagent gave the anomeric disulfide 62 together with the chromophore 63 whose concentration is easy to monitor. The discovery of this alternative assay for MshB activity may accelerate the search for new inhibitors of MshB due to its ease of application and monitoring.

\section{Conclusion}

This discovery of a new MshB assay by Jardine and his group, who himself is a graduate of the early days of MSH chemistry, is the perfect conclusion to this perspective article because it provides the best message for the South African chemist reader. That message is that MSH chemistry is rich in opportunities provided that we adopt an attitude of painstaking evaluation and modification of what is already known and that we remain open to new challenges, which may open the doors to unexpected treasures just beneath the surface.

I hope that this passionate discussion of all the chemistry around this simple yet intriguing molecule has been sufficient to convince the reader that indeed mycothiol is a great molecule, a Great South African Molecule.

\section{References}

1 J. Szychowski, J-F. Truchon and Y.L. Bennani, Natural products in medicine: transformational outcome of synthetic chemistry, J. Med. Chem., 2014, 57, 9292-9308.

2 Nobel Foundation http://www.nobelprize.org/nobel_prizes/ (accessed 11 June 2016).

3 B. Abegaz, Challenges and opportunities for chemistry in Africa, Nat. Chem., 2016, 8, 518-522.

4 South Africa, Department of Science and Technology, Ministerial Review Committee on the Science, Technology and Innovation Landscape in South Africa. 2012.

5 M.T. Davies-Coleman, Natural products research in South Africa: End of an era on land or the beginning of an endless opportunity in the sea?, S. Afr. J. Chem., 2010, 63, 105-113.

6 G.R. Pettit, G.M. Cragg, D.L. Herald, J.M. Schmidt and P. Lohavanijaya, Isolation and structure of combretastatin, Can. J. Chem., 1982, 60, 1374-1376.
7 Zybrestat - Vascular Disrupting Agent and Cancer Therapy. http:// www.drugdevelopment-technology.com/projects/anticancer drug/ (accessed June 11, 2016)

8 M.F. Richardson and F.L. Warren, The Senecio akaloids. Part I. Rosmarinine, J. Chem. Soc., 1943, 452-454.

9 D.A. Mulholland and S.E. Drewes, Global phytochemistry: indigenous medicinal chemistry on track in southern Africa, Phytochemistry, 2004, 65, 769-782.

10 G.W. Perold, The structure of geigerin, J. Chem. Soc., 1957, 47-51.

11 P.A. Jacobi, K.M. Touchette and H.G. Selnick, Bis-heteroannulation: a synthetic approach to geigerin, J. Org. Chem., 1992, 57, 6305-6313.

12 (a) P.S. Steyn, Mycotoxins, general view, chemistry and structure, Toxicol. Lett., 1995, 82, 843-851; (b) P.S. Steyn and R. Vleggaar, Tremorgenic mycotoxins, Progress in the Chemistry of Organic Natural Products, Springer Vienna, 1985, 1-80; (c) A.E. de Jesus, P.S. Steyn, F.R. van Heerden, R. Vleggaar, P.L. Wessels and W.E. Hull, Tremorgenic mycotoxins from Penicillium crustosum: isolation of penitrems A-F and the structure elucidation and absolute configuration of penitrem A, J. Chem. Soc. Perkin Trans. 1, 1983, 1847-1856; (d) A.E. de Jesus, P.S. Steyn, F.R. van Heerden and R. Vleggaar, Structure elucidation of the janthitrems, novel tremorgenic mycotoxins from Penicillium janthinellum, J. Chem. Soc. Perkin Trans. 1, 1984, 697-701; (e) M.E. Cawood, W.C.A. Gelderblom, R. Vleggaar, Y. Behrend, P.G. Thiel and W.F.O. Marasas, Isolation of the fumonisin mycotoxins: A quantitative approach, J. Agric. Food Chem., 1991, 39, 1958-1962; (f) W. Gelderblom, K. Jaskiewicz, W. Marasas, P. Thiel, R. Horak, R. Vleggaar and N. Kriek, Fumonisins - novel mycotoxins with cancer-promoting activity produced by Fusarium moniliforme, Appl. Environ Microbiol., 1988, 54, 1806-1811.

13 J.E. Hirsch, An index to quantify an individual's scientific research output, Proc. Natl. Acad. Sci. USA, 2005, 102, 16569-16572.

14 G. Newton, R. Fahey, G. Cohen and Y. Aharonowitz, Lowmolecular-weight thiols in streptomycetes and their potential role as antioxidants, J. Bacteriol., 1993, 175, 2734-2742.

15 S. Sakuda, A. Isogai, S. Matsumoto, A. Suzuki and K. Koseki, The structure of allosamidin, a novel insect chitinase inhibitor, produced by Streptomyces sp., Tetrahedron Lett., 1986, 27, 2475-2478.

16 S. Sakuda, Z-Y. Zhou and Y. Yamada, Structure of a novel disulfide of 2-(N-acetylcysteinyl) amido-2-deoxy- $\alpha$-D-glucopyran-osyl-myoinositol produced by Streptomyces sp., Biosci. Biotech. Biochem., 1994, 58, 1347-1348.

17 H.S. Spies and D.J. Steenkamp, Thiols of intracellular pathogens. Identification of ovothiol A in Leishmania donovani and structural analysis of a novel thiol from Mycobacterium bovis, Eur. J. Biochem., 1994, 224, 203-213.

18 G.L. Newton, C.A. Bewley, T.J. Dwyer, R. Horn, Y. Aharonowitz, G. Cohen, J. Davies, D.J. Faulkner and R.C. Fahey, The structure of U17 isolated from Streptomyces clavuligerus and its properties as an antioxidant thiol, Eur. J. Biochem., 1995, 230, 821-825.

19 G.L. Newton, K. Arnold, M.S. Price, C. Sherrill, S.B. DelCardayré, Y. 
Aharonowitz, G. Cohen, J. Davies, R.C. Fahey and C. Davis, Distribution of thiols in microorganisms: mycothiol is a major thiol in most actinomycetes, J. Bacteriol., 1996, 178, 1990-1995.

20 (a) C. Bornemann, M.A. Jardine, H.S.C. Spies and D.J. Steenkamp, Biosynthesis of mycothiol: elucidation of the sequence of steps in Mycobacterium smegmatis, Biochem. J., 1997, 325, 623-629; (b) S.G. Broadley, J.C. Gumbart, B.W. Weber, M.J. Marakalala, D.J. Steenkamp and B.T. Sewell, A new crystal form of MshB from Mycobacterium tuberculosis with glycerol and acetate in the active site suggests the catalytic mechanism, Acta Crystallogr., Sect. D: Biol. Crystallogr., 2012, 68, 1450-1459.

21 (a) G.L. Newton, P. Ta, K.P. Bzymek and R.C. Fahey, Biochemistry of the initial steps of mycothiol biosynthesis, J. Biol. Chem., 2006, 281, 33910-33920; (b) G.L. Newton, Y. Av-Gay and R.C. Fahey, $N$-Acetyl-1-D-myo-inosityl-2-amino-2-deoxy- $\alpha$-D-glucopyranoside deacetylase (MshB) is a key enzyme in mycothiol biosynthesis, J. Bacteriol., 2000, 182, 6958-6963; (c) G.L. Newton, N. Buchmeier and R.C. Fahey, Biosynthesis and functions of mycothiol, the unique protective thiol of Actinobacteria, Microbiol. Mol. Biol. Rev., 2008, 72, 471-494; (d) G.L. Newton and R.C. Fahey, Mycothiol biochemistry, Arch. Microbiol., 2002, 178, 388-394; (e) R.C. Fahey, Glutathione analogs in prokaryotes, Biochim. Biophys. Acta, 2013, 1830,3182-3198.

22 (a) F. Fan, M.W. Vetting, P.A. Frantom and J.S. Blanchard, Structures and mechanisms of the mycothiol biosynthetic enzymes, Curr. Op. Chem. Biol., 2009, 13, 451-459; (b) X. Huang, and M. Hernick, Examination of mechanism of $\mathrm{N}$-acetyl-1-D-myo-inosityl-2-amino-2deoxy- $\alpha$-D-glucopyranoside deacetylase (MshB) reveals unexpected role for dynamic tyrosine, J. Biol. Chem., 2012, 287, 10424-10434; (c) V.K. Jothivasan and C.J. Hamilton, Mycothiol: synthesis, biosynthesis and biological functions of the major low molecular weight thiol in actinomycetes, Nat. Prod. Rep., 2008, 25, 1091-1117.

23 A. Harries, Y. Lin, S. Satyanarayana, K. Lönnroth, L. Li, N. Wilson, L. Chauhan, R. Zachariah, M. Baker and C. Jeon, The looming epidemic of diabetes-associated tuberculosis: learning lessons from HIVassociated tuberculosis, Int. J. Tuberc. Lung Dis., 2011, 15, 1436-1445.

24 N.A. Buchmeier, G.L. Newton, T. Koledin and R.C. Fahey, Association of mycothiol with protection of Mycobacterium tuberculosis from toxic oxidants and antibiotics, Mol. Microbiol., 2003, 47, 1723-1732.

25 (a) M. Rawat, G.L. Newton, M. Ko, G.J. Martinez, R.C. Fahey and Y. Av-Gay, Mycothiol-deficient Mycobacterium smegmatis mutants are hypersensitive to alkylating agents, free radicals, and anti biotics, Antimicrob. Agents Chemother., 2002, 46, 3348-3355; (b) D. Sareen, G.L. Newton, R.C. Fahey and N.A. Buchmeier, Mycothiol is essential for growth of Mycobacterium tuberculosis Erdman, J. Bacteriol., 2003, 185, 6736-6740; (c) M. Hernick, Mycothiol: a target for potentiation of rifampin and other antibiotics against Mycobacterium tuberculosis, 2013, 11, 49-67; (d) G. Lamichhane, Novel targets in M. tuberculosis: search for new drugs, Trends Mol. Med., 2011, 17, 25-33; (e) S.S. Nilewar and M.K. Kathiravan, Mycothiol: a promising antitubercular target, Bioorg. Chem., 2014, 52, 62-68.

26 (a) E.K. Rowinsky, The development and clinical utility of the taxane class of antimicrotubule chemotherapy agents, Annu. Rev. Med., 1997, 48,353-374; (b) A. García, V. Bocanegra-García, J.P. Palma-Nicolás and G. Rivera, Recent advances in antitubercular natural products, Eur. J. Med. Chem., 2012, 49, 1-23; (c) B. Gold, M. Pingle, S.J. Brickner, N. Shah, J. Roberts, M. Rundell, W.C. Bracken, T. Warrier, S. Somersan, A. Venugopal, C. Darby, X. Jiang, J.D. Warren, J. Fernandez, O. Ouerfelli, E.L. Nuermberger, A. CunninghamBussel, P. Rath, T. Chidawanyika, H. Deng, R. Realubit, J.F., Glickman and C.F. Nathan, Nonsteroidal anti-inflammatory drug sensitizes Mycobacterium tuberculosis to endogenous and exogenous antimicrobials, Proc. Natl. Acad. Sci. USA, 2012, 109, 16004-16011; (d) A. Zumla, P. Nahid and S.T. Cole, Advances in the development of new tuberculosis drugs and treatment regimens, Nat. Rev. Drug Discovery, 2013, 12, 388-404; (e) I. Abubakar, M. Zignol, D. Falzon, M. Raviglione, L. Ditiu, S. Masham, I. Adetifa, N. Ford, H. Cox, S.D Lawn, B.J. Marais, T.D. McHugh, P. Mwaba, M. Bates, M. Lipman, L. Zijenah, S. Logan, R. McNerney, A. Zumla, K. Sarda, P. Nahid, M. Hoelscher, M. Pletschette, Z.A. Memish, P. Kim, R. Hafner, S. Cole, G.B. Migliori, M. Maeurer, M. Schito and A. Zumla, Drug-resistant tuberculosis: time for visionary political leadership, Lancet Infect. Dis., 2013, 13, 529-539.

27 B. Villemagne, C. Crauste, M. Flipo, A.R. Baulard, B. Déprez and N. Willand, Tuberculosis: the drug development pipeline at a glance, Eur. J. Med. Chem., 2012, 51, 1-16.
28 C. Vilchèze, T. Hartman, B. Weinrick and W.R. Jacobs Jr, Mycobacterium tuberculosis is extraordinarily sensitive to killing by a vitamin Cinduced Fenton reaction, Nat. Commun., 2013, 4, 1881-1890

29 C. Dye, Doomsday postponed? Preventing and reversing epidemics of drug-resistant tuberculosis, Nat Rev. Micro., 2009, 7, 81-87.

30 K. Van Laer, C.J. Hamilton and J. Messens, Low-molecular-weight thiols in thiol-disulfide exchange, Antioxid. Redox Signaling 2013, 18, 1642-1653.

31 G.L. Newton, M.D. Unson, S.J. Anderberg, J.A. Aguilera, N.N. Oh, S.B. delCardayre, Y. Av-Gay and R.C. Fahey, Characterization of Mycobacterium smegmatis mutants defective in 1-D-myo-inositoyl-2amino-2-deoxy- $\alpha$-D-glucopyranoside and mycothiol biosynthesis, Biochem. Biophys. Res. Commun., 1999, 255, 239-244.

32 H. Paritala and K.S. Carroll, New targets and inhibitors of mycobacterial sulfur metabolism, Infect. Disord. Drug Targets, 2013, 13, 85-115.

33 (a) M. Misset-Smits, P.W. van Ophem, S. Sakuda and J.A. Duine, Mycothiol, 1-O-(2'-[N-acetyl-cysteinyl]amido-2'-deoxy- $\alpha$-glucopyranosyl)-myo-inositol, is the factor of NAD/factor-dependent formaldehyde dehydrogenase, Fed. Eur. Biochem. Soc. Lett., 1997, 409, 221-222; (b) T. Jaeger, H. Budde, L Flohe, U. Menge, M. Singh, M. Trujillo and R. Radi, Multiple thioredoxin-mediated routes to detoxify hydroperoxides in Mycobacterium tuberculosis, Arch. Biochem. Biophys., 2004, 423, 182-191; (c) M. Hugo, K. Van Laer, A.M. Reyes, D. Vertommen, J. Messens, R. Radi and M. Trujillo, Mycothiol/mycoredoxin 1-dependent reduction of the peroxiredoxin AhpE from Mycobacterium tuberculosis, J. Biol. Chem., 2014, 289, 5228-5239; (d) H. Antelmann and C.J. Hamilton, Bacterial mechanisms of reversible protein S-thiolation: structural and mechanistic insights into mycoredoxins, Mol. Microbiol., 2012, 86, 759-764; (e) K. Van Laer, L. Buts, N. Foloppe, D. Vertommen, K. Van Belle, K. Wahni, G. Roos, L. Nilsson, L.M. Mateos and M. Rawat, Mycoredoxin-1 is one of the missing links in the oxidative stress defence mechanism of Mycobacteria, Mol. Microbiol., 2012, 86, 787-804; (f) B.K. Chi, T. Busche, K. Van Laer, K. Bäsell, D. Becher, L. Clermont, G.M. Seibold, M. Persicke, J. Kalinowski and J. Messens, Protein S-mycothiolation functions as redox-switch and thiol protection mechanism in Corynebacterium glutamicum under hypochlorite stress, Antioxid. Redox Signaling, 2014, 20, 589-605; (g) E. Ordóñez, K. Van Belle, G. Roos, S. De Galan, M. Letek, J.A. Gil, L. Wyns, L.M. Mateos and J Messens, Arsenate reductase, mycothiol, and mycoredoxin concert thiol/disulfide exchange, J. Biol. Chem., 2009, 284, 15107-15116; (h) X. Huang, E. Kocabas and M. Hernick, The activity and cofactor preferences of $N$-acetyl-1-D-myo-inosityl-2-amino-2-deoxy- $\alpha$-D-glucopyranoside deacetylase (MshB) change depending on environmental conditions, J. Biol. Chem., 2011, 286, 20275-20282; (i) E. Kocabas, H. Liu and M. Hernick, Identity of cofactor bound to mycothiol conjugate amidase (Mca) influenced by expression and purification conditions, BioMetals 2015, 28, 755-763; (j) Y-B. Liu, M-X. Long, Y-J. Yin, M-R. Si, L. Zhang, Z-Q. Lu, Y. Wang and X-H. Shen, Physiological roles of mycothiol in detoxification and tolerance to multiple poisonous chemicals in Corynebacterium glutamicum, Arch. Microbiol., 2013, 195, 419-429; (k) R. Attarian, C. Bennie, H. Bach and Y. Av-Gay, Glutathione disulfide and S-nitrosoglutathione detoxification by Mycobacterium tuberculosis thioredoxin system, FEBS Lett., 2009, 583, 32153220.

34 (a) M.A. Jardine, H.S.C Spies, C.M. Nkambule, D.W. Gammon and D.J. Steenkamp, Synthesis of mycothiol, 1D-1-O-(2-[N-acetyl-Lcysteinyl]amino-2-deoxy- $\alpha$-D-glucopyranosyl)-myo-inositol, principal low molecular mass thiol in the actinomycetes, Bioorg. Med. Chem., 2002, 10, 875-881; (b) G.M. Nicholas, P. Kovac and C.A. Bewley, Total synthesis and proof of structure of mycothiol bimane, J. Am. Chem. Soc., 2002, 124, 3492-3493; (c) S. Lee and J.P.N. Rosazza, First total synthesis of mycothiol and mycothiol disulfide, Org. Lett., 2004, 6, 365-368; (d) M.P. Patel and J.S. Blanchard, Synthesis of Des-myoInositol mycothiol and demonstration of a mycobacterial specific reductase activity, J. Am. Chem. Soc., 1998, 120, 11538-11539; (e) Z. Liu, $\mathrm{Y}$. Wu and G. Liu, Efficient and convenient total synthesis of mycothiol on a large scale, J. Chin. Pharm. Sci., 2015, 24, 347-355; (f) S. Manabe and Y. Ito, Mycothiol synthesis by an anomerization reaction through endocyclic cleavage, Beilstein J. Org. Chem., 2016, 12, 328-333; (g) K. Ajayi, V.V. Thakur, R.C. Lapo and S. Knapp, Intramolecular $\alpha$-Glucosaminidation: synthesis of mycothiol, Org. Lett., $2010,12,2630-2633$.

35 (a) X. Huang and M. Hernick, Automated docking studies provide insights into molecular determinants of ligand recognition by 
$N$-acetyl-1-D-myo-inosityl-2-amino-2-deoxy- $\alpha$-D-glucopyranoside deacetylase (MshB), Biopolymers, 2014, 101, 406-417; (b) M-T. Gutierrez-Lugo and C.A. Bewley, Susceptibility and mode of binding of the Mycobacterium tuberculosis cysteinyl transferase mycothiol ligase to tRNA synthetase inhibitors, Bioorg. Med. Chem. Lett., 2011, 21, 2480-2483; (c) G.M. Nicholas, L.L. Eckman, P. Kovac, S. OteroQuintero and C.A. Bewley, Synthesis of 1-D-and 1-L-myo-inosityl2 - $N$-acetamido-2-deoxy- $\alpha$-D-glucopyranoside establishes substrate specificity of the Mycobacterium tuberculosis enzyme AcGI deacetylase, Bioorg. Med. Chem., 2003, 11, 2641-2647; (d) J. Mahadevan, G.M. Nicholas and C.A. Bewley, Solution conformations of mycothiol bimane, 1-D-GlcNAc- $\alpha$-(1-1)-D-myo-Ins and 1-D-GlcNAc- $\alpha-(1-1)-\mathrm{L}-$ myo-Ins, J. Org. Chem., 2003, 68, 3380-3386.

36 (a) D.W. Gammon, R. Hunter, D.J. Steenkamp and T.T. Mudzunga, Synthesis of 2-deoxy-2-C-alkylglucosides of myo-inositol as possible inhibitors of a $\mathrm{N}$-deacetylase enzyme in the biosynthesis of mycothiol, Bioorg. Med. Chem. Lett., 2003, 13, 2045-2049; (b) R. Slattegard, D.W. Gammon and S. Oscarson, Synthesis of fused bicyclic thioglycosides of $\mathrm{N}$-acylated glucosamine as analogues of mycothiol Carbohydr. Res., 2007, 342, 1943-1946; (c) D.W. Gammon, D.J. Steenkamp, V. Mavumengwana, M.J. Marakalala, T.T. Mudzunga, R. Hunter and M. Munyololo, Conjugates of plumbagin and phenyl2-amino-1-thioglucoside inhibit MshB, a deacetylase involved in the biosynthesis of mycothiol, Bioorg. Med. Chem., 2010, 18, 2501-2514 (d) I.L. Rogers, D.W. Gammon and K.J. Naidoo, Conformational preferences of plumbagin with phenyl-1-thioglucoside conjugates in solution and bound to MshB determined by aromatic association, Carbohydr. Res., 2013, 371, 52-60.

37 (a) C.M. Nkambule, N.W. Kwezi, H.H. Kinfe, M.G. Nokwequ, D.W. Gammon, S. Oscarson and E. Karlsson, Efficient regioselective protection of myo-inositol via facile protecting group migration, Tetrahedron, 2011, 67, 618-623; (b) M.G. Nokwequ, C.M. Nkambule and D.W. Gammon, A serendipitous formation of a cysteine-bridged disaccharide, S. Afr. J. Chem., 2014, 67, 180-183; (c) M.G. Nokwequ, C.M. Nkambule and D.W. Gammon, Armed-disarmed effect on the stability of cysteine thioglucosides, Carbohydr. Res., 2012, 359, 18-23.

38 (a) S. Knapp, S. Gonzalez, D.S. Myers, L.L. Eckman and C.A. Bewley, Shortcut to mycothiol analogues, Org. Lett., 2002, 4, 4337-4339; (b) S. Knapp, B. Amorelli, E. Darout, C.C. Ventocilla, L.M. Goldman, R.A. Huhn and E.C. Minnihan, A family of mycothiol analogues, J. Carboydr. Chem., 2005, 24, 103-130.

39 (a) M-T. Gutierrez-Lugo, H. Baker, J. Shiloach, H. Boshoff and C.A. Bewley, Dequalinium, a new inhibitor of Mycobacterium tuberculosis mycothiol ligase identified by high-throughput screening, J. Biomol. Screening, 2009, 14, 643-652; (b) G.M. Nicholas, L.L. Eckman, S. Ray, R.O. Hughes, J.A. Pfefferkorn, S. Barluenga, K.C. Nicolaou and C.A. Bewley, Bromotyrosine-derived natural and synthetic products as inhibitors of mycothiol-S-conjugate amidase, Bioorg. Med. Chem. Lett. 2002, 12, 2487-2490; (c) G.M. Nicholas, G.L. Newton, R.C. Fahey and C.A. Bewley, Novel bromotyrosine alkaloids: inhibitors of mycothiol S-conjugate amidase, Org. Lett., 2001, 3, 1543-1545; (d) B.B. Metaferia, B.J. Fetterolf, S. Shazad-ul-Hussan, M. Moravec, J.A. Smith, S. Ray, M-T. Gutierrez-Lugo and C.A. Bewley, Synthesis of natural product-inspired inhibitors of Mycobacterium tuberculosis mycothiolassociated enzymes: the first inhibitors of GlcNAc-Ins deacetylase, J. Med. Chem., 2007, 50, 6326-6336.

40 G.L. Newton, N. Buchmeier, J.J. La Clair and R.C. Fahey, Evaluation of NTF1836 as an inhibitor of the mycothiol biosynthetic enzyme MshC in growing and non-replicating Mycobacterium tuberculosis, Bioorg. Med. Chem., 2011, 19, 3956-3964.

41 L.H. Miller and X. Su, Artemisinin: discovery from the Chinese herbal garden, Cell, 2011, 146, 855-858.

42 S.W. Riordan, J.J. Field, H.M. Corkran, N. Dasyam, B.L. Stocker M.S.M. Timmer, J.E. Harvey and P.H. Teesdale-Spittle, Synthesis of mycothiol conjugate analogues and evaluation of their antimycobacterial activity, Bioorg. Med. Chem. Lett., 2015, 25, 2152-2155.

43 Z. Kamenik, S. Kadlcik, B. Radojevic, P. Jiraskova, M. Kuzma, R. Gazak, L. Najmanova, J. Kopecky and J. Janata, Deacetylation of mycothiolderived 'waste product' triggers the last biosynthetic steps of lincosamide antibiotics, Chem. Sci., 2016, 7, 430-435.

44 P. Dandawate, K. Vemuri, K.V. Swamy, E.M. Khan, M. Sritharan and S. Padhye, Synthesis, characterization, molecular docking and anti-tubercular activity of Plumbagin-Isoniazid analog and its $\beta$-cyclodextrin conjugate, Bioorg. Med. Chem. Lett., 2014, 24, 50705075 .
45 (a) A. Mahapatra, S.P.N. Mativandlela, B. Binneman, P.B. Fourie, C.J. Hamilton, J.J.M. Meyer, F. Van der Kooy, P. Houghton and N. Lall, Activity of 7-methyljuglone derivatives against Mycobacterium tuberculosis and as subversive substrates for mycothiol disulfide reductase, Bioorg. Med. Chem., 2007, 15, 7638-7646; (b) S.P. Mativandlela, T. Muthivhi, H. Kikuchi, Y. Oshima, C. Hamilton, A.A. Hussein, M.L. van der Walt, P.J. Houghton and N. Lall, Antimycobacterial flavonoids from the leaf extract of Galenia africana, J. Nat. Prod., 2009, 72, 2169-2171.

46 C.M. Nkambule and D.W. Gammon, Progress in the synthesis of mycothiol, its biosynthetic precursors and analogues. Carbohydrate Chemistry, 2016, 41, 124-148.

47 K.M. Sureshan, S. Devaraj and M.S. Shashidhar, Regioselective O-acylation of myo-inositol 1,3,5-orthoesters: dependence of regioselectivity on the stoichiometry of the base, Tetrahedron, 2009, 65, 2703-2710.

48. (a) C-C. Chung, M.M.L. Zulueta, L.T. Padiyar and S-C. Hung, Desymmetrization of 2,4,5,6-tetra-O-benzyl-D-myo-inositol for the synthesis of mycothiol, Org. Lett., 2011, 13, 5496-5499; (b) P.S. Patil and S-C. Hung, Synthesis of mycobacterial triacylated phosphatidylinositol dimannoside containing an acyl lipid chain at 3-O of inositol, Org. Lett., 2010, 12, 2618-2621; (c) P.S. Patil and S-C. Hung, Total synthesis of phosphatidylinositol dimannoside: a cell-envelope component of Mycobacterium tuberculosis, Chem. - Eur. J., 2009, 15, 1091-1094.

49 (a) S.J. Conway, J. Gardiner, S.J.A. Grove, M.K. Johns, Z-Y. Lim, G.F. Painter, D.E.J.E. Robinson, C. Schieber, J.W. Thuring, L.S.M. Wong, M-X. Yin, A.W. Burgess, B. Catimel, P.T. Hawkins, N.T. Ktistakis, L.R. Stephens and A.B. Holmes, Synthesis and biological evaluation of phosphatidylinositol phosphate affinity probes, Org. Biomol. Chem., 2010, 8, 66-76; (b) J. Lindberg, L. Öhberg, P.J. Garegg and P. Konradsson, Efficient routes to glucosamine-myo-inositol derivatives, key building blocks in the synthesis of glycosylphosphatidylinositol anchor substances, Tetrahedron, 2002, 58, 1387-1398.

50 B. Fraser-Reid, Z. Wu, U.E. Udodong and H. Ottosson, Armed/ disarmed effects in glycosyl donors: rationalization and sidetracking, J. Org. Chem., 1990, 55, 6068-6070.

51 (a) M.N. Kamat and A.V. Demchenko, Revisiting the armeddisarmed concept rationale: S-benzoxazolyl glycosides in chemoselective oligosaccharide synthesis, Org. Lett., 2005, 7, 3215-3218; (b) H.D. Premathilake, L.K. Mydock and A.V. Demchenko, Superarming common glycosyl donors by simple 2-O-benzoyl-3,4,6tri-O-benzyl protection, J. Org. Chem., 2010, 75, 1095-1100; (c) D. Crich, Mechanism of a chemical glycosylation reaction, Acc. Chem. Res., 2010, 43, 1144-1153; (d) D. Crich and I. Sharma, Influence of the $\mathrm{O} 3$ protecting group on stereoselectivity in the preparation of C-mannopyranosides with 4,6-O-benzylidene protected donors, J. Org. Chem., 2010, 75, 8383-8391; (e) B.S. Komarova, M.V. Orekhova, Y.E. Tsvetkov and N.E. Nifantiev, Is an acyl group at O-3 in glucosyl donors able to control $\alpha$-stereoselectivity of glycosylation? The role of conformational mobility and the protecting group at O-6, Carbohydr. Res., 2014, 384, 70-86.

52 (a) J.P. Yasomanee and A.V. Demchenko, Hydrogen-bond mediated aglycone delivery (HAD): a highly stereoselective synthesis of 1,2-cis $\alpha$-D-glucosides from common glycosyl donors in the presence of bromine, Chem - Eur. J., 2015, 21, 6572-6581; (b) K.S. Kim and D-H. Suk, Remote Participation of protecting groups at remote positions of donors in glycosylations, Trends Glycosci. Glycotech., 2011, 23, 53-66.

53 (a) E.A. Mensah and H.M. Nguyen, Nickel-catalyzed stereoselective formation of $\alpha$-2-deoxy-2-amino glycosides, J. Am. Chem. Soc., 2009, 131, 8778-8780; (b) E.A. Mensah, F. Yu and H.M. Nguyen, NickelCatalyzed stereoselective glycosylation with $\mathrm{C}(2)-N$-substituted benzylidene $\mathrm{D}$-glucosamine and galactosamine trichloroacetimidates for the formation of 1,2-cis-2-amino glycosides. Applications to the synthesis of heparin disaccharides, GPI anchor pseudodisaccharides, and $\alpha$-GalNAc, J. Am. Chem. Soc., 2010, 132, 1428814302; (c) M.S. McConnell, F. Yu and H.M. Nguyen, Nickel-catalyzed $\alpha$-glycosylation of $\mathrm{C}(1)$-hydroxyl D-myo-inositol: a formal synthesis of mycothiol, Chem. Commun., 2013, 49, 4313-4315; (d) F. Yu and H.M. Nguyen, Studies on the selectivity between nickel-catalyzed 1,2-cis2 -amino glycosylation of hydroxyl groups of thioglycoside acceptors with C(2)-substituted benzylidene $N$-phenyl trifluoroacetimidates and intermolecular aglycon transfer of the sulfide group, J. Org. Chem., 2012, 77, 7330-7343.

54 (a) M.D. Unson, G.L. Newton, K.F. Arnold, C.E. Davis and R.C. Fahey, 
Improved methods for immunoassay of mycothiol, J. Clinical Microbiol., 1999, 37, 2153-2157; (b) M.D. Unson, G.L. Newton, C. Davis and R.C. Fahey, An immunoassay for the detection and quantitative determination of mycothiol, J. Immunol. Methods 1998, 214, 29-39.

55 C.M. Holsclaw, W.B. Muse, K.S. Carroll and J.A. Leary, Mass spectrometric analysis of mycothiol levels in wild-type and mycothiol disulfide reductase mutant Mycobacterium smegmatis, Int. J. Mass Spec., 2011, 305, 151-156.

56 C.J. Hamilton, R.M. Finlay, M.J. Stewart and A. Bonner, Mycothiol disulfide reductase: a continuous assay for slow time-dependent inhibitors, Anal. Biochem., 2009, 388, 91-96.

$57 \mathrm{X}$. Huang and M. Hernick, A fluorescence-based assay for measuring $N$-acetyl-1-D-myo-inosityl-2-amino-2-deoxy- $\alpha$-D-glucopyranoside deacetylase activity, Anal. Biochem., 2011, 414, 278-281.

58 D.A. Lamprecht, N.O. Muneri, H. Eastwood, K.J. Naidoo, E. Strauss and A. Jardine, An enzyme-initiated Smiles rearrangement enables the development of an assay of MshB, the GlcNAc-Ins deacetylase of mycothiol biosynthesis, Org. Biomol. Chem., 2012, 10, 5278-5288. 